\title{
Paroxysmal Extreme Pain Disorder
}

National Cancer Institute

\section{Source}

National Cancer Institute. Paroxysmal Extreme Pain Disorder. NCI Thesaurus. Code C125385.

A very rare, autosomal dominant inherited disorder caused by mutations in the SCN9A gene. It is characterized by skin redness and flushing and attacks of severe pain. The pain attacks usually last seconds to minutes. 